\title{
Vibration-Based Analysis for Detecting Turbocharger Blade Defect on High-Power Diesel Generator
}

\author{
Metaga Jeremi Sogoba, Badié Diourté, Moussa Magara Traoré \\ Ecole Nationale d'Ingénieurs Abderhamane Baba TOURE (ENI-ABT), Bamako, Mali \\ Email:infos@eni-abt.ml
}

How to cite this paper: Sogoba, M.J., Diourté, B. and Traoré, M.M. (2020) Vibration-Based Analysis for Detecting Turbocharger Blade Defect on High-Power Diesel Generator. World Journal of Mechanics, 10, $1-10$.

https://doi.org/10.4236/wjm.2020.101001

Received: December 29, 2019

Accepted: January 11, 2020

Published: January 14, 2020

Copyright ( 2020 by author(s) and Scientific Research Publishing Inc. This work is licensed under the Creative Commons Attribution International License (CC BY 4.0).

http://creativecommons.org/licenses/by/4.0/

\begin{abstract}
This study is concerned with 12-MW capacity turbochargers on diesel power generators. These are generators equipped with 18 cylinders. Our previous studies [1] showed that the processing of vibration signature collected from a power generator is very complex, insomuch the dominant vibration remains the one originating from explosion frequency in the diesel generator cylinders, with a fairly high number of cylinders. This vibration drowns out all other possible vibrations, which can expose defects. The study at hand is focused on turbochargers with $20,940 \mathrm{rpm}$, while the rotation speed in the diesel engine is $600 \mathrm{rpm}$ only. With the turbocharger rotating at very high speed, it results in severe mechanical constraints on the rotor shaft in the turbocharger and its related organs (turbine blades). The wear of turbine blades can result in breakdowns in the turbocharger. This article is an attempt to early detect defaults in turbine blades based on vibration signature that can be experimentally determined. We noted in our investigations that a diesel engine and its turbochargers do not bear the same mechanic loads. While the diesel engine is the seat of violent shocks brought about by explosions in cylinders, the turbochargers are driven by the action of exhaust gas from explosions, without being affected by explosion shocks. The study found that explosion frequency in the diesel engine cylinders, which disrupted the vibration signals in the diesel engine and alternator, did not impact on the vibration signals in the turbocharger. We experimentally determined, following several campaigns of measurements, a vibration signature on the turbochargers under study, which corresponds to a defect in turbine blades.
\end{abstract}

\section{Keywords}

Vibration Signature, Fast Fourier Transform Method (FFT), Turbocharger, Turbine Blades 


\section{Introduction}

We undertook this study as a result of repeated breakdowns in turbochargers on some power generating sets, to early detect causes of the breakdowns. Chief among them is the wear of turbine blades. During the normal functioning of the turbocharger the blades are likely to wear out over time. If the worn-out blades are not replaced in time breakdowns can occur on the turbocharger, which led us to determine the global vibration level of the turbochargers under investigation. The global vibration level is measured according to a standardized threshold, or obtained experimentally [2]. The wear of turbine blades occurs in global vibration level above the reference threshold. To detect the defect, the signals are interpreted with the help of signal processing methods [3]. The signals collected from the turbochargers are stationary [4]. There are many methods for signal processing. For the purposes of this study, Fast Fourier Transform (FFT) has been selected, for it is easy to implement and can be efficiently applied for processing stationary signals. Thus, we determined a vibration signature corresponding to the wear of the turbine blades. We found that the explosion frequency of the diesel engine does not disturb the spectra collected on the turbochargers.

\section{Method}

Signals collected on diesel generating sets are mostly cyclostationary [5] [6]. The first studies on cyclostationary signals can be traced back to the 1950s. In telecommunications, cyclostationarity received much attention, in particular since the 1980s; its use in mechanics appeared more recently, though [7]. A power generating set is characterised by the frequency of a rotating crankshaft and the frequency of explosions in the diesel engine cylinders. Disruptions may occur when the two frequencies are overlaid. These result in random cyclic signals; in other words, these are cyclostationary signals.

A random process is strictly cyclostationary with period $T$, if its probability density being periodic of period $T$.

$$
P_{x}(t)=P_{x}(t+n T), \forall(t, n) \in \mathbb{R} \times \mathbb{Z}
$$

Period $T$ is called cyclic period.

A random process is solely stationary, if its probability density is invariant by time translation.

$$
P_{x}(t)=P_{x}(t+\Delta t), \forall(t, \Delta t) \in \mathbb{R}^{2}
$$

Turbochargers on a diesel generator are insulated from mechanic shocks resulting from explosions in the diesel engine cylinders, which explains why the signals produced by the turbochargers are stationary. These signals can be properly processed using Fast Fourier Transform method. This method is obtained from discrete Fourier transform. Fast Fourier Transform (FFT) is an algorithm for calculating discrete Fourier transform (DFT). We selected this algorithm for its efficiency. On the one hand, it is an algorithm that makes possible filtering by 
altering the spectrum, and using the inverse transform (finite impulse response filter), on the other hand. A discrete Fourier transform of $T$ size (number of samples) is given by the formula:

$$
X(k)=\sum_{t=0}^{T-1} x(t) \mathrm{e}^{\left(-2 \pi j \frac{k t}{T}\right)} \text { avec } k=0, \cdots, T-1
$$

For example, $t=2 n$ if $t$ is even and $t=2 n+1$ if $t$ is odd. We arrive at the rapid Fourier transform $(F F T) . X(k)$ is then written [8] [9]:

$$
X(k)=\sum_{n=0}^{N-1} x(2 n) \mathrm{e}^{\left(-2 \pi j \frac{k 2 n}{T}\right)}+\sum_{n=0}^{N-1} x(2 n+1) \mathrm{e}^{\left(-2 \pi j \frac{k(2 n+1)}{T}\right)}
$$

\subsection{Determining Explosion Frequency in Diesel Engine}

Explosion frequency is an important parameter for diesel generators since the primary source of vibration is related to this frequency. It is determined based on the crankshaft positioning and the number of cylinders in diesel engine. The frequency of explosion is given by the following formula:

$$
\begin{gathered}
F_{\text {explo }}=\frac{\text { number of explosions per cycle }}{\text { number of turns per cycle }} \\
f_{0}=\frac{1}{\text { turn }} \\
F_{\text {explo }}=\frac{\text { number of explosions per cycle }}{2} f_{0}
\end{gathered}
$$

with $f_{0}$ : rotation frequency of the diesel engine.

The diesel engine under study has 18 cylinders (Table 1). Explosion occurs 2 by 2 , or 9 explosions per cycle. Following the formula (7), explosion frequency is $45 \mathrm{~Hz}$.

\subsection{Measures}

Measurements were carried out on a diesel power generator at Balingue plant, belonging to the public energy utility of Mali. The instruments that have been used for measurements included a $100 \mathrm{mv} / \mathrm{g}$-sensitivity accelerometer, a signal collector with 12,800 line capacity, and signal processing software. Measurements were made at standard measurement points (Figure 1) by fitting the

Table 1. Characteristics of the power generating set investigated.

\begin{tabular}{cc}
\multicolumn{2}{c}{ Characteristics of the Power Generating Set } \\
\hline Operating mode & Basic operation \\
Type of engine & $4 \mathrm{X} 18 \mathrm{~V} 38 \mathrm{~B}$ \\
Engine output power & $12.150 \mathrm{Kw}$ \\
Engine rotation speed & $600 \mathrm{rpm}$ \\
Rotation direction & Counter-clockwise \\
Fuel & HFO \\
Turbocharger rotation speed & $20.940 \mathrm{rpm}$ \\
\hline
\end{tabular}




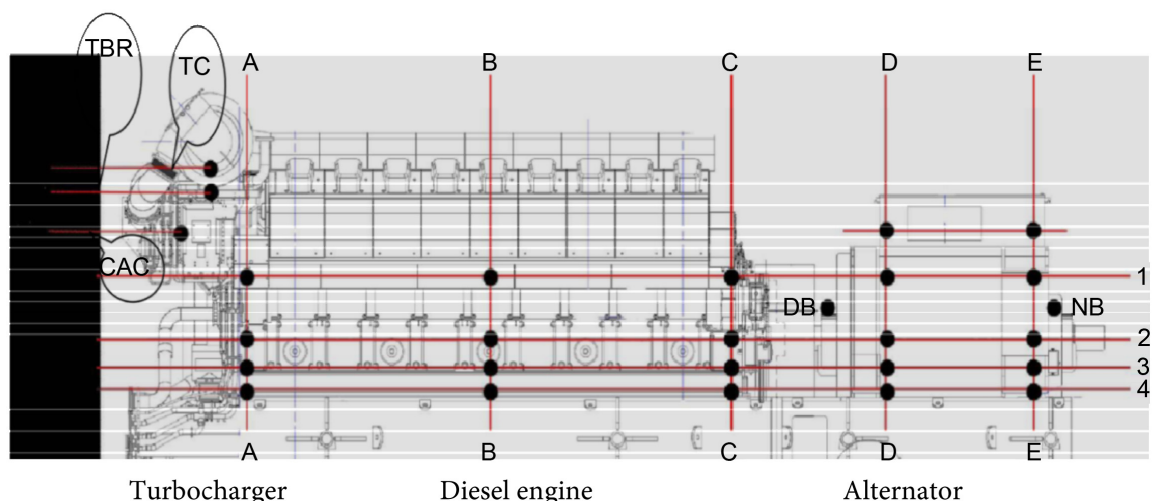

Figure 1. Configuration of measurement points.

accelerometer at these points, while the generator was running at full capacity (11 MW). We selected 6 measurement points on the turbochargers 8 measurement points on the diesel engine, and 8 measurement points on the alternator. On each measurement point, 3 measures were performed following 3 directions: axial, radial vertical and radial horizontal.

\section{Results}

\subsection{Global Vibration Level Analysis}

Tables 2(a)-7(a) show the global vibration level of the turbocharger with worn-out blades. Tables 2(b)-7(b) show the global vibration level of the turbocharger with healthy blades.

It has been noted that the whole range of the diesel engine vibration levels are below the permissible limit of $45 \mathrm{~mm} / \mathrm{s}$ for the diesel side (Table 2 and Table 3). As for the alternator, the limit is $20 \mathrm{~mm} / \mathrm{s}$. All the measurements on the alternators are below this limit (Table 4 and Table 5).

As no measurement on the diesel and alternator reaches these limits $(45 \mathrm{~mm} / \mathrm{s}$ and $20 \mathrm{~mm} / \mathrm{s}$ ), the vibration status of the diesel engine and alternator is sound [10] [11].

On the other side, the maximum vibration measured on the turbochargers was $20.8 \mathrm{~mm} / \mathrm{s}$ in side A (Table 6) and $22.5 \mathrm{~mm} / \mathrm{s}$ in side B (Table 7) compared to a limit of $18 \mathrm{~mm} / \mathrm{s}$ in the first measurement campaign. That has led us to undertake investigations in an attempt to pinpoint what was causing this abnormal vibration. After the turbochargers have been repaired, we obtained a vibration of $16.5 \mathrm{~mm} / \mathrm{s}$, at the same measurement point (Table 7).

\subsection{Spectral Analysis}

We can see that on the faulty turbocharger where turbine blades are worn out [Figure 2(b)], the spectrum [Figure 2(a)] is different from the spectrum [Figure $3(a)$ ] of the healthy turbocharger [Figure 3(b)]. These spectra are obtained in frequency domain. Their occurrence is linked to the state of the turbocharger [12]. If a break occurs, it manifests itself in a separate spectral typology. This indicates 
Table 2. Vibration level of the diesel engine side A.

(a)

\begin{tabular}{|c|c|c|c|c|c|c|c|c|c|c|c|c|}
\hline \multicolumn{13}{|c|}{ Measurement Points } \\
\hline Parameters & laAX & $1 \mathrm{aRH}$ & $1 \mathrm{aRV}$ & $2 \mathrm{aAX}$ & $2 \mathrm{aRH}$ & $2 \mathrm{aRV}$ & $3 \mathrm{aAX}$ & $3 \mathrm{aRH}$ & $3 \mathrm{aRV}$ & $4 \mathrm{aAX}$ & $4 \mathrm{aRH}$ & $4 \mathrm{aRV}$ \\
\hline Acceleration $\left(\mathrm{m} / \mathrm{s}^{2}\right)$ & 6.66 & 3.54 & 7.29 & 1.80 & 0.895 & 1.81 & 2.41 & 2.19 & 2.80 & 0.682 & 0.512 & 0.558 \\
\hline Velocity (mm/s) & 10.7 & 9.50 & 17.8 & 4.82 & 9.27 & 11.3 & 5.20 & 7.70 & 8.88 & 2.90 & 4.95 & 7.98 \\
\hline Unbalance fo $\left(\mathrm{m} / \mathrm{s}^{2}\right)$ & 0.0029 & 0.012 & 0.0059 & 0.0031 & 0.015 & 0.0089 & 0.0016 & 0.0074 & 0.0048 & 0.0012 & 0.013 & 0.0077 \\
\hline Alignment $\mathrm{H} 2\left(\mathrm{~m} / \mathrm{s}^{2}\right)$ & 0.0057 & 0.031 & 0.024 & 0.0056 & 0.016 & 0.017 & 0.0040 & 0.039 & 0.019 & 0.010 & 0.017 & 0.018 \\
\hline Alignment H3 $\left(\mathrm{m} / \mathrm{s}^{2}\right)$ & 0.0029 & 0.012 & 0.012 & 0.0079 & 0.0026 & 0.015 & 0.0047 & 0.012 & 0.017 & 0.0057 & 0.012 & 0.011 \\
\hline
\end{tabular}

(b)

\begin{tabular}{|c|c|c|c|c|c|c|c|c|c|c|c|c|}
\hline \multicolumn{13}{|c|}{ Measurement Points } \\
\hline Parameters & $1 \mathrm{aAX}$ & $1 \mathrm{aRH}$ & $1 \mathrm{aRV}$ & $2 \mathrm{aAX}$ & $2 \mathrm{aRH}$ & $2 \mathrm{aRV}$ & $3 a A X$ & $3 \mathrm{aRH}$ & $3 \mathrm{aRV}$ & $4 \mathrm{aAX}$ & $4 \mathrm{aRH}$ & $4 \mathrm{aRV}$ \\
\hline Acceleration $\left(\mathrm{m} / \mathrm{s}^{2}\right)$ & 6.54 & 3.74 & 8.29 & 1.85 & 0.852 & 2.04 & 2.71 & 2.30 & 2.45 & 0.719 & 0.537 & 0.599 \\
\hline Velocity $(\mathrm{mm} / \mathrm{s})$ & 11.1 & 10.2 & 21.1 & 5.16 & 9.86 & 12.4 & 6.28 & 8.42 & 8.22 & 3.47 & 5.04 & 8.67 \\
\hline Alignment H2 (m/ $\left.\mathrm{s}^{2}\right)$ & 0.0082 & 0.031 & 0.021 & 0.0052 & 0.013 & 0.016 & 0.0054 & 0.038 & 0.014 & 0.011 & 0.014 & 0.016 \\
\hline Alignment H3 $\left(\mathrm{m} / \mathrm{s}^{2}\right)$ & 0.0065 & 0.014 & 0.0059 & 0.0062 & 0.0025 & 0.013 & 0.00090 & 0.010 & 0.012 & 0.0044 & 0.012 & 0.012 \\
\hline
\end{tabular}

Table 3. Vibration level of the diesel engine side B.

(a)

\begin{tabular}{|c|c|c|c|c|c|c|c|c|c|c|c|c|}
\hline \multicolumn{13}{|c|}{ Measurement Points } \\
\hline Parameters & $1 \mathrm{bAX}$ & $1 \mathrm{bRH}$ & $1 \mathrm{bRV}$ & $2 \mathrm{bAX}$ & $2 \mathrm{bRH}$ & $2 \mathrm{bRV}$ & $3 \mathrm{bAX}$ & $3 \mathrm{bRH}$ & $3 \mathrm{bRV}$ & $4 \mathrm{bAX}$ & $4 \mathrm{bRH}$ & $4 \mathrm{bRV}$ \\
\hline Acceleration $\left(\mathrm{m} / \mathrm{s}^{2}\right)$ & 8.44 & 5.40 & 8.51 & 1.92 & 0.867 & 1.69 & 2.94 & 2.37 & 2.99 & 0.849 & 0.604 & 0.700 \\
\hline Velocity $(\mathrm{mm} / \mathrm{s})$ & 13.8 & 11.8 & 20.3 & 4.74 & 8.97 & 12.4 & 6.65 & 8.50 & 10.2 & 3.41 & 4.94 & 9.75 \\
\hline Unbalance $\mathrm{f} 0\left(\mathrm{~m} / \mathrm{s}^{2}\right)$ & 0.0026 & 0.011 & 0.0060 & 0.0027 & 0.015 & 0.020 & 0.0023 & 0.0073 & 0.0066 & 0.0011 & 0.0016 & 0.020 \\
\hline Alignment $\mathrm{H} 2\left(\mathrm{~m} / \mathrm{s}^{2}\right)$ & 0.0076 & 0.034 & 0.018 & 0.0061 & 0.017 & 0.017 & 0.011 & 0.041 & 0.017 & 0.012 & 0.0069 & 0.014 \\
\hline Alignment $\mathrm{H} 3\left(\mathrm{~m} / \mathrm{s}^{2}\right)$ & 0.013 & 0.011 & 0.011 & 0.0068 & 0.0026 & 0.0055 & 0.0076 & 0.0075 & 0.010 & 0.0084 & 0.0079 & 0.0038 \\
\hline
\end{tabular}

(b)

\begin{tabular}{|c|c|c|c|c|c|c|c|c|c|c|c|c|}
\hline \multicolumn{13}{|c|}{ Measurement Points } \\
\hline Parameters & lbAX & $1 \mathrm{bRH}$ & $1 \mathrm{bRV}$ & $2 \mathrm{bAX}$ & $2 \mathrm{bRH}$ & $2 \mathrm{bRV}$ & 3bAX & $3 \mathrm{bRH}$ & 3bRV & $4 \mathrm{bAX}$ & $4 \mathrm{bRH}$ & $4 \mathrm{bRV}$ \\
\hline Acceleration $\left(\mathrm{m} / \mathrm{s}^{2}\right)$ & 7.32 & 6.04 & 9.49 & 1.94 & 0.855 & 1.85 & 3.69 & 2.75 & 3.08 & 0.949 & 0.570 & 0.668 \\
\hline Velocity (mm/s) & 12.4 & 13.3 & 23.4 & 4.84 & 9.72 & 12.7 & 8.41 & 9.60 & 10.8 & 3.59 & 4.88 & 9.80 \\
\hline Unbalance fo $\left(\mathrm{m} / \mathrm{s}^{2}\right)$ & 0.0035 & 0.012 & 0.00074 & 0.0034 & 0.013 & 0.020 & 0.0019 & 0.0098 & 0.0010 & 0.0014 & 0.0023 & 0.019 \\
\hline Alignment $\mathrm{H} 2\left(\mathrm{~m} / \mathrm{s}^{2}\right)$ & 0.0054 & 0.033 & 0.025 & 0.0027 & 0.013 & 0.014 & 0.0086 & 0.041 & 0.020 & 0.0069 & 0.0056 & 0.011 \\
\hline Alignment $\mathrm{H} 3\left(\mathrm{~m} / \mathrm{s}^{2}\right)$ & 0.0081 & 0.012 & 0.018 & 0.0069 & 0.0036 & 0.011 & 0.0075 & 0.012 & 0.012 & 0.0084 & 0.014 & 0.0023 \\
\hline
\end{tabular}


Table 4. Vibration level of the alternator side A.

(a)

\begin{tabular}{cccccccccccccc}
\hline & \multicolumn{10}{c}{ Measurement Points } \\
\hline Parameters & $5 \mathrm{aAX}$ & $5 \mathrm{aRH}$ & $5 \mathrm{aRV}$ & $6 \mathrm{aAX}$ & $6 \mathrm{aRH}$ & $6 \mathrm{aRV}$ & $7 \mathrm{aAX}$ & $7 \mathrm{aRH}$ & $7 \mathrm{aRV}$ & $8 \mathrm{aAX}$ & $8 \mathrm{aRH}$ & $8 \mathrm{aRV}$ \\
\hline Acceleration (m/s $)$ & 0.485 & 0.580 & 0.297 & 0.445 & 0.494 & 0.249 & 1.64 & 0.553 & 0.766 & 0.770 & 0.500 & 0.929 \\
Velocity (mm/s) & 10.8 & 16.1 & 7.18 & 12.3 & 14.1 & 11.8 & 4.99 & 7.98 & 6.63 & 4.54 & 6.13 & 11.9 \\
Unbalance f0 (m/s $)$ & 0.023 & 0.014 & 0.013 & 0.026 & 0.017 & 0.056 & 0.013 & 0.0059 & 0.025 & 0.0099 & 0.0082 & 0.052 \\
Alignment H2 (m/s) & 0.034 & 0.0069 & 0.033 & 0.033 & 0.034 & 0.028 & 0.014 & 0.008 & 0.024 & 0.014 & 0.0075 & 0.037 \\
Alignment H3 (m/s) & 0.021 & 0.013 & 0.027 & 0.025 & 0.016 & 0.011 & 0.0088 & 0.014 & 0.024 & 0.0070 & 0.025 & 0.036 \\
\hline
\end{tabular}

(b)

\begin{tabular}{|c|c|c|c|c|c|c|c|c|c|c|c|c|}
\hline \multicolumn{13}{|c|}{ Measurement Points } \\
\hline Parameters & $5 \mathrm{aAX}$ & $5 \mathrm{aRH}$ & $5 \mathrm{aRV}$ & $6 \mathrm{aAX}$ & $6 \mathrm{aRH}$ & $6 \mathrm{aRV}$ & $7 \mathrm{aAX}$ & $7 \mathrm{aRH}$ & $7 \mathrm{aRV}$ & $8 \mathrm{aAX}$ & $8 \mathrm{aRH}$ & $8 \mathrm{aRV}$ \\
\hline Acceleration $\left(\mathrm{m} / \mathrm{s}^{2}\right)$ & 0.514 & 0.609 & 0.409 & 0.477 & 0.573 & 0.323 & 0.901 & 4.37 & 0.523 & 0.898 & 0.569 & 0.924 \\
\hline Velocity (mm/s) & 12.5 & 14.0 & 11.1 & 13.2 & 14.9 & 13.7 & 4.87 & 11.5 & 6.87 & 5.02 & 6.64 & 12.7 \\
\hline Alignment $\mathrm{H} 2\left(\mathrm{~m} / \mathrm{s}^{2}\right)$ & 0.045 & 0.0062 & 0.032 & 0.038 & 0.032 & 0.026 & 0.017 & 0.0016 & 0.018 & 0.017 & 0.0088 & 0.033 \\
\hline Alignment $\mathrm{H} 3\left(\mathrm{~m} / \mathrm{s}^{2}\right)$ & 0.037 & 0.029 & 0.018 & 0.033 & 0.020 & 0.0069 & 0.010 & 0.018 & 0.036 & 0.0074 & 0.043 & 0.039 \\
\hline
\end{tabular}

Table 5. Vibration level of the alternator side B.

(a)

\begin{tabular}{|c|c|c|c|c|c|c|c|c|c|c|c|c|}
\hline \multicolumn{13}{|c|}{ Measurement Points } \\
\hline Parameters & $5 \mathrm{aAX}$ & $5 \mathrm{aRH}$ & $5 \mathrm{aRV}$ & $6 \mathrm{aAX}$ & $6 \mathrm{aRH}$ & $6 \mathrm{aRV}$ & $7 \mathrm{aAX}$ & $7 \mathrm{aRH}$ & $7 \mathrm{aRV}$ & $8 \mathrm{aAX}$ & $8 \mathrm{aRH}$ & $8 \mathrm{aRV}$ \\
\hline Acceleration $\left(\mathrm{m} / \mathrm{s}^{2}\right)$ & 0.533 & 0.646 & 0.308 & 0.502 & 0.481 & 0.262 & 1.94 & 0.563 & 0.825 & 1.01 & 0.533 & 0.946 \\
\hline Velocity (mm/s) & 13.9 & 15.0 & 6.96 & 13.5 & 14.0 & 12.1 & 5.11 & 8.36 & 6.99 & 4.54 & 6.39 & 12.9 \\
\hline Unbalance fo $\left(\mathrm{m} / \mathrm{s}^{2}\right)$ & 0.025 & 0.014 & 0.0056 & 0.023 & 0.017 & 0.056 & 0.0087 & 0.0056 & 0.024 & 0.0057 & 0.0066 & 0.058 \\
\hline Alignment $\mathrm{H} 2\left(\mathrm{~m} / \mathrm{s}^{2}\right)$ & 0.043 & 0.0078 & 0.036 & 0.037 & 0.033 & 0.027 & 0.015 & 0.0086 & 0.026 & 0.014 & 0.0095 & 0.033 \\
\hline Alignment H3 $\left(\mathrm{m} / \mathrm{s}^{2}\right)$ & 0.055 & 0.015 & 0.029 & 0.015 & 0.018 & 0.0060 & 0.0020 & 0.014 & 0.022 & 0.0039 & 0.026 & 0.015 \\
\hline
\end{tabular}

(b)

\begin{tabular}{|c|c|c|c|c|c|c|c|c|c|c|c|c|}
\hline \multicolumn{13}{|c|}{ Measurement Points } \\
\hline Parameters & $5 \mathrm{aAX}$ & $5 \mathrm{aRH}$ & $5 \mathrm{aRV}$ & $6 \mathrm{aAX}$ & $6 \mathrm{aRH}$ & $6 \mathrm{aRV}$ & $7 \mathrm{aAX}$ & $7 \mathrm{aRH}$ & $7 \mathrm{aRV}$ & $8 \mathrm{aAX}$ & $8 \mathrm{aRH}$ & $8 \mathrm{aRV}$ \\
\hline Acceleration $\left(\mathrm{m} / \mathrm{s}^{2}\right)$ & 0.668 & 0.584 & 0.364 & 0.537 & 0.562 & 0.330 & 1.12 & 0.673 & 0.812 & 0.809 & 0.550 & 0.885 \\
\hline Velocity (mm/s) & 18.4 & 13.4 & 10.0 & 14.6 & 14.9 & 14.1 & 4.35 & 8.70 & 8.73 & 4.56 & 6.90 & 13.9 \\
\hline Unbalance f0 $\left(\mathrm{m} / \mathrm{s}^{2}\right)$ & 0.025 & 0.011 & 0.0034 & 0.023 & 0.012 & 0.060 & 0.0040 & 0.0065 & 0.027 & 0.0053 & 0.0059 & 0.062 \\
\hline Alignment $\mathrm{H} 2\left(\mathrm{~m} / \mathrm{s}^{2}\right)$ & 0.046 & 0.0075 & 0.031 & 0.038 & 0.034 & 0.025 & 0.0087 & 0.0099 & 0.026 & 0.014 & 0.0097 & 0.027 \\
\hline Alignment $\mathrm{H} 3\left(\mathrm{~m} / \mathrm{s}^{2}\right)$ & 0.071 & 0.019 & 0.013 & 0.0081 & 0.024 & 0.0025 & 0.0054 & 0.018 & 0.026 & 0.0081 & 0.035 & 0 \\
\hline
\end{tabular}


Table 6. Vibration level of the turbocharger side B.

(a)

\begin{tabular}{cccccccccc}
\hline \multicolumn{10}{c}{ Measurement Points } \\
\hline Parameters & TbAX & TbRH & TbRV & BbAX & BbRH & BbRV & CbAX & CbRH & CbRV \\
\hline Acceleration $\left(\mathrm{m} / \mathrm{s}^{2}\right)$ & 13.8 & 7.19 & 8.72 & 3.38 & 2.46 & 3.76 & 5.50 & 6.66 & 4.38 \\
Velocity $(\mathrm{mm} / \mathrm{s})$ & 19.4 & 12.6 & 22.5 & 6.64 & 9.66 & 8.02 & 9.00 & 9.44 & 9.43 \\
\hline
\end{tabular}

(b)

\begin{tabular}{cccccccccc}
\hline \multicolumn{10}{c}{ Measurement Points } \\
\hline Parameters & TbAX & TbRH & TbRV & BbAX & BbRH & BbRV & CbAX & CbRH & CbRV \\
\hline Acceleration $\left(\mathrm{m} / \mathrm{s}^{2}\right)$ & 17.5 & 10.2 & 15.7 & 2.58 & 3.66 & 4.33 & 4.10 & 3.23 & 2.31 \\
Velocity $(\mathrm{mm} / \mathrm{s})$ & 14.9 & 12.7 & 16.5 & 10.3 & 6.35 & 8.46 & 10.1 & 6.91 & 7.83 \\
\hline
\end{tabular}

Table 7. Vibration level of the turbocharger side A.

(a)

\begin{tabular}{ccccccccccc}
\hline \multicolumn{10}{c}{ Measurement Points } \\
\hline Parameters & TaAX & TaRH & TaRV & BaAX & BaRH & BaRV & CaAX & CaRH & CaRV \\
\hline Acceleration $\left(\mathrm{m} / \mathrm{s}^{2}\right)$ & 14.0 & 9.28 & 7.17 & 3.22 & 2.83 & 4.19 & 3.86 & 6.70 & 4.50 \\
Velocity $(\mathrm{mm} / \mathrm{s})$ & 14.8 & 10.8 & 20.8 & 4.95 & 9.82 & 7.85 & 8.43 & 9.50 & 9.54 \\
\hline
\end{tabular}

(b)

\begin{tabular}{cccccccccc}
\hline \multicolumn{1}{c}{ Measurement Points } \\
\hline Parameters & TaAX & TaRH & TaRV & BaAX & BaRH & BaRV & CaAX & CaRH & CaRV \\
\hline Acceleration $\left(\mathrm{m} / \mathrm{s}^{2}\right)$ & 11.4 & 9.25 & 7.15 & 2.53 & 3.99 & 2.91 & 7.12 & 2.41 & 3.89 \\
Velocity $(\mathrm{mm} / \mathrm{s})$ & 12.7 & 11.1 & 17.3 & 9.97 & 5.72 & 7.78 & 10.3 & 6.46 & 7.87 \\
\hline
\end{tabular}

that turbochargers, while part of the diesel engine, are fully insulated from the mechanical shocks originating from the diesel engine cylinders. They work like a usual rotating machine. The Fast Fourier Transform method, in frequency domain, correctly applies to turbochargers for power generating set. As a consequence, the spectral analysis enabled us to obtain relevant results. High vibration at frequency $\mathrm{C} 1: 3478.51 \mathrm{~Hz}$ has been detected in the turbine wheel. It has 39 blades and turns at $349 \mathrm{~Hz}$.

$4 \mathrm{C} 1: 13.9 \mathrm{kHz}$ corresponds to almost 39 times the rotation speed of the turbine wheel $(13.6 \mathrm{kHz})$. This shows that 4 out of the 39 blades are worn out. On dismantling the turbocharger, we, indeed, found that out of the 39 blades in the turbine wheel 4 were worn-out. We found that the signals collected from the diesel engine and alternator are cyclostationary and carried by explosion frequency in the diesel engine cylinders. On the other hand, the signals collected from the turbochargers are stationary and insulated from explosion frequency, at $45 \mathrm{~Hz}$. This frequency is no more the dominant one. In our previous studies, the spectra collected from the diesel engine and alternator of the diesel power generators 
- C1 $(3450.39 \mathrm{~Hz},[6.62 \mathrm{~g}, 2.99 \mathrm{~mm} / \mathrm{s}, 0.13837 \mu \mathrm{m}])$

$\mathrm{mm} / \mathrm{s}$ [RMS]: Turbo2A TCaAXS-10 Hz-5kHz 17/12/2018 13:24:50

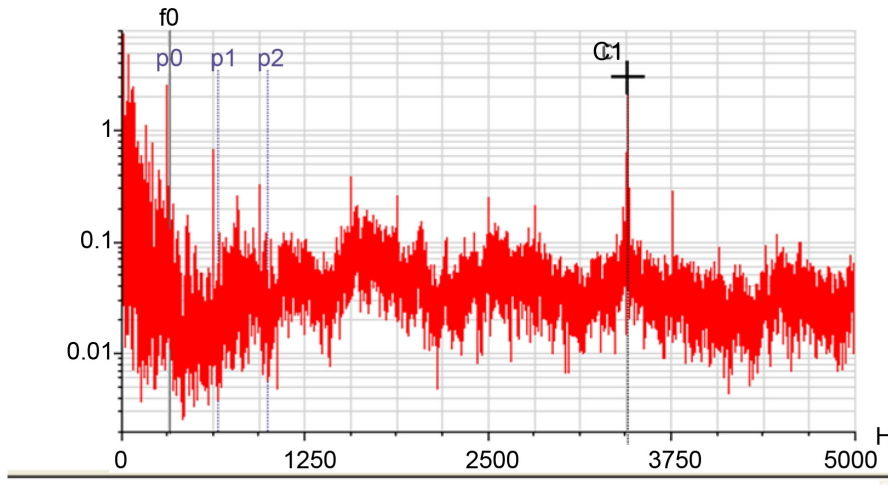

Turbo2A TCaAX S-10 Hz-5k 」 C1 $3450.39 \mathrm{~Hz}$

$6.62 \mathrm{~g}, 2.99 \mathrm{~mm} / \mathrm{s}, 0.13837$

fo: VitRot $333 \mathrm{~Hz}$

p1: Lignage $\mathrm{H} 2666 \mathrm{~Hz}[+/-1.1]$

22:Lignage H3 999Hz [+/- 1.1]

Parc Equipements|Turbo2A

TCaAX--A-0000

17/12/2018 13:16:19 - 0-5000Hz - g - 12801Pts

(a)

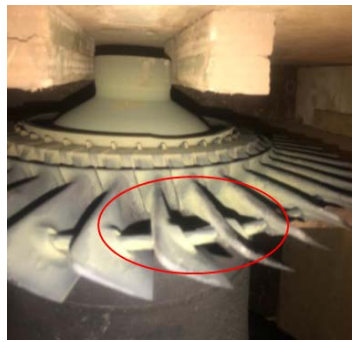

(b)

Figure 2. Defective turbine blade.

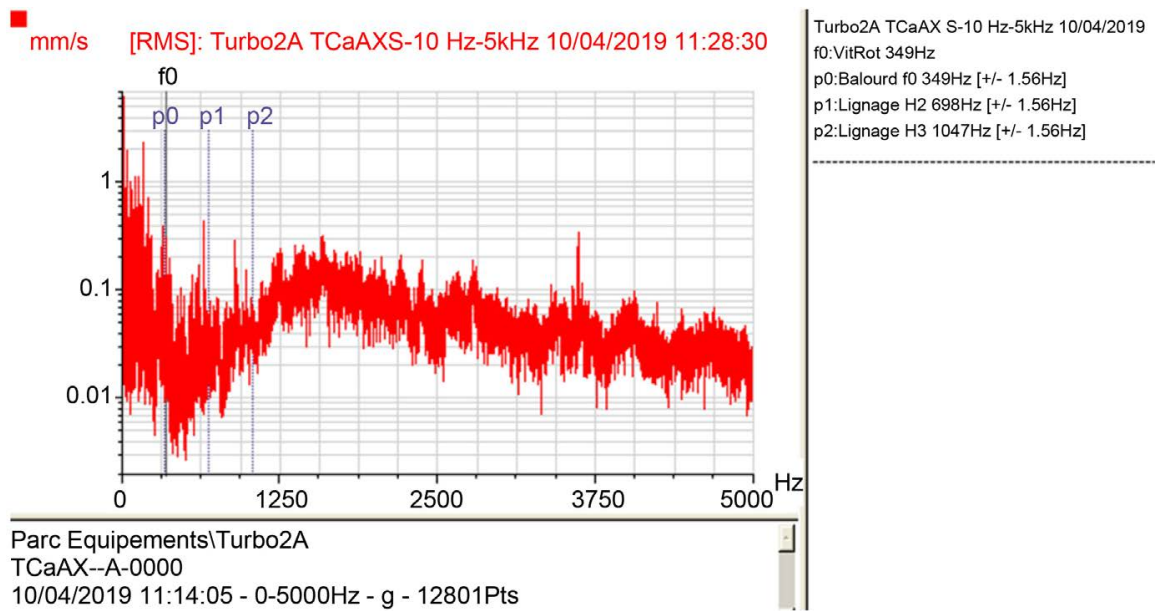

(a)

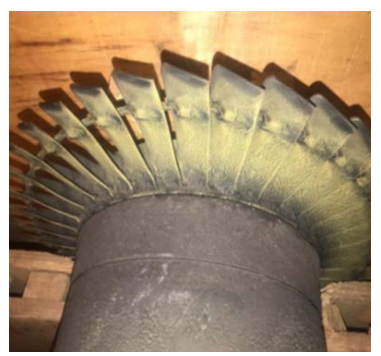

(b)

Figure 3. Healthy turbine blade. 
were constantly carried by the explosion frequency in the diesel engine (Figure 4 and Figure 5). These spectra did not change, in frequency domain, even with a defect.

\section{Discussion}

The measurement points on the turbocharger part were in places where the temperature was very high. This constraint has led us to repeat the same measures several times to ensure the accuracy of these measures. We found relevant results from the Fast Fourier Transform method. However, it is possible to improve these results by testing other methods. In perspective, we intend to test the time-frequency method on high power diesel generators and compare these results with those found with the Fast Fourier Transform method (FFT).

\section{Conclusions}

The explosion frequency in diesel engine has no impacts on the turbochargers. They work as a usual rotating machine. Therefore, it was possible to analyse the

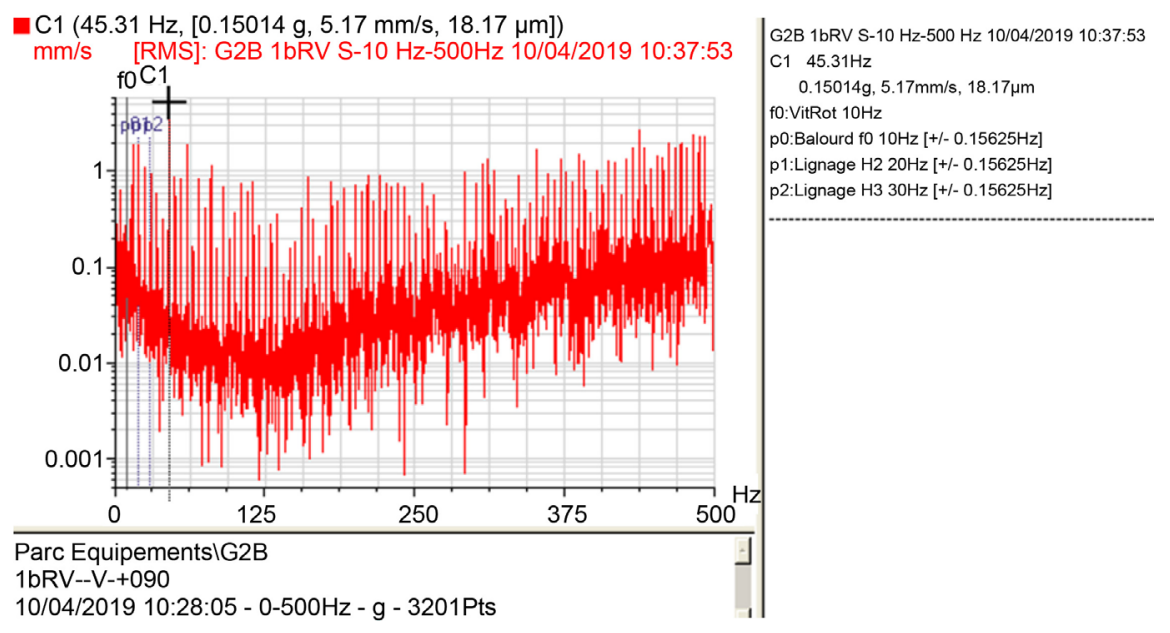

Figure 4. Spectra of diesel engine.

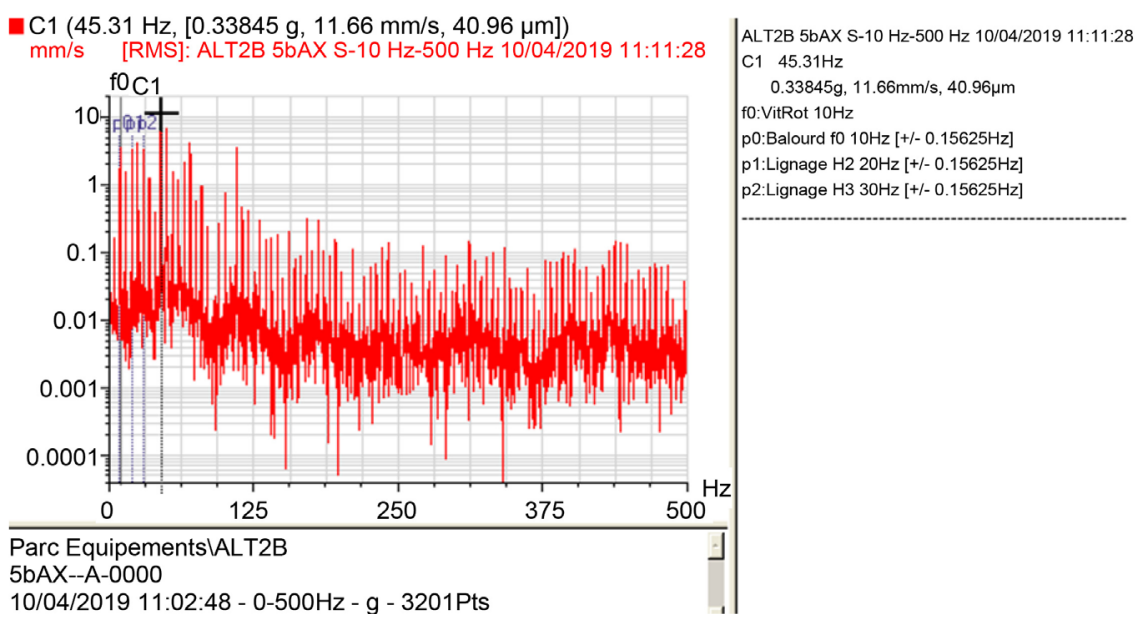

Figure 5. Spectra of alternator. 
signals collected with the help of Fast Fourier Transform method in frequency domain. The vibration signature changes according to the sound health or the defect in the turbocharger. On the other hand, our previous studies have shown that the vibration signature of a power generating set along the diesel part and the alternator part does not change, even with a defect, in terms of frequency domain. This vibration signature was always born by the explosion frequency in the diesel engine.

The study found that explosion frequency in the diesel engine cylinders, which disrupted the vibration signals in the diesel engine and alternator, did not impact on the vibration signals in the turbocharger.

Through experiment, we determined a vibration signal corresponding to an actual defect in the turbocharger turbine, including detecting the defect, the cause of the defect, as well as the extent and severity of the given defect (wear of 4 blades).

\section{Conflicts of Interest}

The authors declare no conflicts of interest regarding the publication of this paper.

\section{References}

[1] Metaga, J.S., Saïd, G. and Badié, D. (2015) Early Detection of Abnormal Vibrations on High-Power Diesel Generator. International Journal on Mechanical Engineering and Robotics, 6.

[2] Basseville, M. and Nikiforov, I. (1993) Detection of Abrupt Changes: Theory and Applications. Prentice Hall, Bergen.

[3] Dubuisson, B. (1990) Diagnostic par reconnaissance des forms. Editions Hermes.

[4] Metaga, J.S., Badié, D. and Lamissa, D. (2018) Vibration Analysis-Based Diagnosis of High-Power Diesel Generator Turbocharger. International Journal of Engineering and Advanced Technology (IJEAT), 8.

[5] Mathieu, D. (2010) Diagnostic de groupes électrogènes diesels par analyse de la vitesse de rotation du vilebrequin. thèse de doctorat, 193.

[6] Bonnardot, F., Zohbi, A., El Badaoui, M. and Guillet, F. (2003) Aide à l'interprétation de signaux cyclostationnaires. CNRIUT Tarbes, 347.

[7] Braun, S. (2001) Mechanical Signature Analysis. Academic Press, Cambridge, 282.

[8] Bellanger, M. (1987) Traitement numérique du signal. Masson Paris, 643

[9] Castanie, F. (1997) Traitement Numérique du Signal. 2. Méthodes Avancées, Édition ENSEEIHT, 546.

[10] Indian Standard (2012) Norme ISO 8528-9.

[11] Association Française de Normalisation (1995) Norme ISO 10816-1.

[12] Sidahmed, M. and Grenier, Y. (2004) Le traitement du signal en mécanique. Recueil de conférence CETIM. 